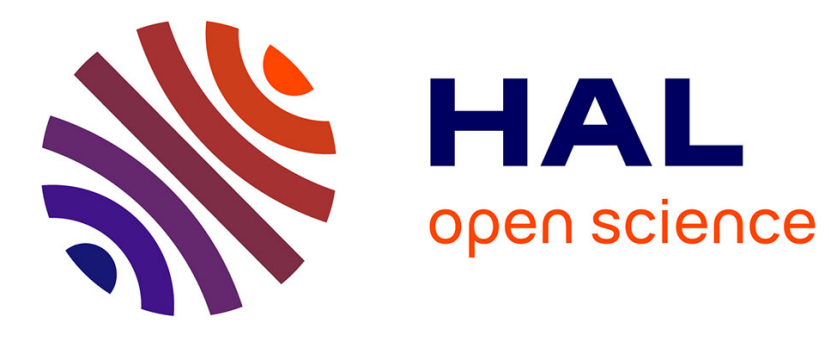

\title{
Real-world costs of illness of Hodgkin and the main B-Cell Non-Hodgkin lymphomas in France
}

Michael Mounié, Nadège Costa, Cécile Conte, Dominique Petiot, Didier

Fabre, Fabien Despas, Maryse Lapeyre-Mestre, Guy Laurent, Nicolas Savy, Laurent Molinier

\section{To cite this version:}

Michael Mounié, Nadège Costa, Cécile Conte, Dominique Petiot, Didier Fabre, et al.. Real-world costs of illness of Hodgkin and the main B-Cell Non-Hodgkin lymphomas in France. Journal of Medical Economics, 2020, 23 (3), pp.235-242. 10.1080/13696998.2019.1702990 . hal-02533775

\section{HAL Id: hal-02533775 \\ https://hal.science/hal-02533775}

Submitted on 9 Apr 2020

HAL is a multi-disciplinary open access archive for the deposit and dissemination of scientific research documents, whether they are published or not. The documents may come from teaching and research institutions in France or abroad, or from public or private research centers.
L'archive ouverte pluridisciplinaire HAL, est destinée au dépôt et à la diffusion de documents scientifiques de niveau recherche, publiés ou non, émanant des établissements d'enseignement et de recherche français ou étrangers, des laboratoires publics ou privés. 


\title{
Real-world costs of illness of Hodgkin and the main B-Cell Non- Hodgkin lymphomas in France
}

\author{
Michael Mounié, Nadège Costa, Cécile Conte, Dominique Petiot, Didier Fabre, Fabien Despas, Maryse \\ Lapeyre-Mestre, Guy Laurent, Nicolas Savy, and Laurent Molinier
}

\section{QUERY SHEET}

This page lists questions we have about your paper. The numbers displayed at left are hyperlinked to the location of the query in your paper.

The title and author names are listed on this sheet as they will be published, both on your paper and on the Table of Contents. Please review and ensure the information is correct and advise us if any changes need to be made. In addition, please review your paper as a whole for typographical and essential corrections.

Your PDF proof has been enabled so that you can comment on the proof directly using Adobe Acrobat. For further information on marking corrections using Acrobat, please visit http://journalauthors.tandf.co.uk/production/acrobat.asp; https://authorservices.taylorandfrancis.com/how-to-correct-proofs-with-adobe/

The CrossRef database (www.crossref.org/) has been used to validate the references.

\section{AUTHOR QUERIES}

Q1 Please provide department/division name for affiliation 'c'.

Q2 Please note that the journal requires a minimum of 5 keywords. Please insert additional keywords accordingly.

Q3 The sense of the sentence "The post-treatment period long were chosen to take into account the different healthcare ..." is not clear. Please check that it reads correctly or supply a revised version.

Q4 The ORCID details of the authors have been validated against ORCID registry. Please check the ORCID ID details of the authors.

Q5 Please provide English translation for [4] reference list entry.

Q6 Please provide English translation for [5] reference list entry.

Q7 Please provide English translation for [28] reference list entry.

Q8 Please provide volume number and page range for [33] reference list entry.

Q9 Please provide English translation for [34] reference list entry. 


\section{Real-world costs of illness of Hodgkin and the main B-Cell Non-Hodgkin lymphomas in France}

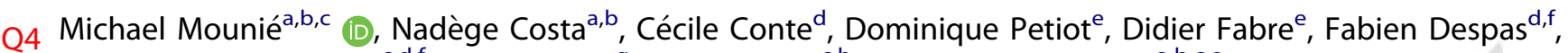
Maryse Lapeyre-Mestre ${ }^{c, d, f}$, Guy Laurent ${ }^{g}$, Nicolas Savy ${ }^{c, h}$ and Laurent Molinier ${ }^{a, b, c, e}$

aUnité d'Evaluation Médico-Economique, Centre Hospitalier Universitaire, Toulouse, France; ${ }^{\mathrm{b}}$ Institut National de la Santé et de la Recherche Médicale - INSERM, Unité Mixte de Recherche-UMR 1027, Toulouse, France; 'Université Toulouse III Paul Sabatier, Toulouse, France;

01 'Laboratoire de Pharmacologie Médicale, facultés de Médecine, Université Toulouse III Paul Sabatier, Toulouse, France; ${ }^{\circ}$ Département d'Information Médicale, Centre Hospitalier Universitaire, Toulouse, France; ${ }^{f}$ Service de Pharmacologie Clinique, CIC 1436, CHU Toulouse, Toulouse, France; ${ }^{9}$ Service d'hématologie CHU Toulouse, Institut Universitaire du Cancer-Oncopôle de Toulouse, Toulouse, France; ${ }^{\text {Institut }}$ Mathématiques de Toulouse, UMR 5219, CNRS, Toulouse, France

\section{ABSTRACT}

Background: Lymphomas are costly diseases that suffer from a lack of detailed economic information, notably in a real-world setting. Decision-makers are increasing the search for Real-World Evidence (RWE) to assess the impact, in real-life, of healthcare management and to support their public decisions. Thus, we aimed to assess the real-world net costs of the active treatment phases of adult Hodgkin Lymphoma (HL), Follicular Lymphoma (FL) and Diffuse Large B Cell Lymphoma (DLBCL).

Methods: We performed a retrospective cohort study using population-based data from a national representative sample of the French population covered by the health insurance system. Cost analysis was performed from the French health insurance perspective and took into account direct and sick leave compensation costs $(€ 2,018)$. Healthcare costs were studied over the active treatment phase. We used multivariate modeling to adjust cost differences between lymphoma subtypes.

Results: Analyses were performed on 224 lymphoma patients and 896 controls. The mean additional monthly costs due to $H L$, FL and DLBCL patients were respectively $€ 5,188, € 3,242$ and $€ 7,659$ for the active treatment phase. The main additional cost driver was principally inpatient stay (hospitalization costs and costly cancer-related drugs), followed by outpatient medication and productivity loss. When adjusted, DLBCL remains significantly the most costly lymphoma subtype.

Conclusion: This study provides an accurate assessment of the main lymphoma subtypes related cost with high magnitude of details in a real-world setting. We underline where potential cost saving could be realized via the use of biosimilar medication, and where lymphoma management could be improved with the early management of adverse events.

\section{KEY POINTS}

- This is one of the first studies which assess the additional cost of lymphoma in Europe, according the main sub-types of lymphoma and with real-world database.

- The additional monthly cost due to $\mathrm{HL}, \mathrm{FL}$ and $\mathrm{DLBCL}$ patients were respectively $€ 5,188$, $€ 3,242$ and $€ 7,659$ for the active treatment phase and the main additional cost driver was principally inpatient stay (i.e. hospitalization costs and additional inpatient medicines, notably rituximab), followed by outpatient medication and productivity loss.

- This study provides an accurate and detailed lymphoma subtype cost description and comparison which supply data for efficiency evaluations and will allow French health policy to improve lymphoma management.

\section{ARTICLE HISTORY}

Received 5 June 2019

Revised 24 October 2019

Accepted 22 November 2019

\section{KEYWORDS}

Lymphoma; cost evaluation;

French health insurance;

real-world evidence

\section{JEL CLASSIFICATION CODES} 118; D24

\section{Introduction}

Lymphomas are malignant hemopathies separated into two main subtypes: Hodgkin Lymphoma (HL) and Non Hodgkin Lymphoma (NHL). They account together for approximately $3-4 \%$ of cancers worldwide, placing them to the 6 th rank of cancers in $2011^{1}$. In France, the annual incidence of $\mathrm{HL}$ and $\mathrm{NHL}$ were respectively estimated to 1,757 and 11,512 new cases in $2012^{2} . \mathrm{HL}$ are B-cell neoplasms and $\mathrm{NHL}$ are divided into B-cell and T/NK-cell neoplasms where B-cell NHL (B-NHL) are the most frequent, notably represented by Follicular Lymphoma (FL) and Diffuse Large B-Cell Lymphoma $(\mathrm{DLBCL})^{3}$. The 5 -years net survival of $\mathrm{HL}$ is equal to $85 \%$ and varies widely according to sub-types for B-NHL with $87 \%$ for $\mathrm{FL}$ and $57 \%$ for DLBCL ${ }^{4}$.

CONTACT Michael Mounié mounie.m@chu-toulouse.fr $=$ Unité d'Evaluation Médico-Economique, Département d'Information Médicale, Centre Hospitalier Universitaire, 2 Rue Viquerie, 31300 Toulouse Cedex 09, France

(-) Supplemental data for this article is available online at https://doi.org/10.1080/13696998.2019.1702990. 
The type and duration of treatment depend on lymphoma stages and sub-types. Treatment of lymphoma is mainly based on drug strategies combining conventional cytotoxic chemotherapy with monoclonal immunotherapy, rituximab, for B-NHL ${ }^{5}$. Lymphoma patients may be treated by immunotherapy, radiation therapy and surgery ${ }^{6,7}$. The active treatment phase is characterized by high toxicity with important magnitude of Adverse Events (AEs) ${ }^{8}$. The diagnosis, treatments and AEs may lead to important physical and psychological vulnerability ${ }^{8,9}$. Thus, the high consumption of care and the resulting number of hospitalizations lead to a significant cost supported by the social health insurance which should be assessed through a Cost-Of-Illness (COI) study.

The aim of a COI study is to identify and measure the costs of a particular disease. COI outcome tells how much society is spending on a particular disease and the amount that would be saved if the disease was eradicated ${ }^{10}$. They reveal the different cost components and their relative societal burden. $\mathrm{COI}$ studies help health policy makers to rationalize health care expenditure by identifying areas where potential economic savings can be realized ${ }^{11}$. Likewise, these studies supply useful economic information to assess innovation in healthcare management.

Nowadays, decision makers are increasing interest for Real-World Evidence (RWE) ${ }^{12}$. It allows to assess the impact, in real-life, of healthcare management and to guide health authority in their public decisions. Nevertheless, only a few studies assessing the cost of lymphoma in real-world settings were found in Europe ${ }^{13}$ or in North America ${ }^{14-18}$. They were focused on special treatments, particular line of treatments or AEs and they did not finely describe cost components of the active treatment phase. Only two cost-effectiveness studies have assessed lymphoma's costs in France, but not in real-world setting ${ }^{19,20}$.

In this context, our aims were to assess direct and sick leave compensation costs during the active treatment phase of $\mathrm{HL}, \mathrm{FL}$ and $\mathrm{DLBCL}$ patients according to a populationbased real-world database and to identify the most important cost components, notably rituximab as it is the main medication used for B-NHL.

\section{Method}

\subsection{Study design, setting and population}

We performed a population-based, retrospective, cohort study using a representative random sample of the French national health insurance database ("Système National des Données de Santé" (SNDS)), called the "Echantillon Généraliste des Bénéficiaires" (EGB).

The SNDS is a national medical and administrative database, allowing access to health care consumption and corresponding reimbursements for $98.8 \%$ of the French population ${ }^{21}$. The EGB database is a representative sample according to age and sex corresponding to $1 / 97$ of SNDS population and includes demographic data, ambulatory care reimbursement (including drug dispensing), inpatient care data, medical data (Long-Term Diseases (LTD) diagnoses), and characteristics of healthcare providers ${ }^{22}$. Patients may be enrolled in a special scheme called LTD which allows the reimbursement of $100 \%$ of disease-related costs.

This was an observational study on anonymous data. In accordance with French legislation, approval by an ethics committee was not required (French Law on Privacy: National Commission of Information Technology and Liberty Decision No. 89-117).

\subsection{Identification of the study population}

In France, most of lymphoma patients inevitably receive treatment in the frame of day hospital. Patients generally stay less than one night but generate a Diagnosis Related Group (DRG) related inpatient stay coded with the International Classification of Disease, 10th revision (ICD-10). Three different diagnoses could be coded, together or not, to define the purpose of the inpatient stay: the Main Diagnosis (MD), Related Diagnosis (RD) and Associated Diagnosis (AD). Study population was then identified using inpatient care data through these diagnoses according to a validated incident identification lymphoma case algorithm ${ }^{23}$. The algorithm considers a patient as lymphoma patient if he has at least a MD of lymphoma or an MD of chemotherapy in combination with a RD or AD of lymphoma. HL (ICD-10 code: C81), FL (ICD-10 code: C82) and DLBCL (ICD-10 code: C833) patients were considered. Exclusion period of prevalent lymphomas and inclusion period of incident lymphomas was ranged respectively from $01 / 03 / 2007$ to $28 / 02 / 2009$ and from $01 / 03 / 2009$ to $28 / 02 / 2013$. Data were available until $31 /$ $12 / 2015$.

Study period was the active treatment phase identified during the maximum range of 01/03/2009 and 31/12/2015 and defined by: (1) an index date per patient as the first ICD10 lymphoma discriminant code minus 21 days. (2) The end of the active treatment phase defined by the date of the last ICD-10 code of lymphoma management if there are no more discriminant ICD-10 codes of lymphoma management associated during the following 12 weeks. The 12 weeks period after the last ICD-10 discriminant code of lymphoma management will be identified as the "post-treatment period". This period allows us to define if the active treatment phase is over or if it always runs. Active treatment phase is fluctuant according to each lymphoma identified. Online resource 1 summarizes how incident lymphoma and lymphoma active treatment period are identified. Lymphoma discriminant management codes correspond to a MD of lymphoma alone as those described above or a MD or RD code of chemotherapy, radiotherapy or a code of the main complication management associated with a MD, a RD or an $A D$ code of lymphoma. These codes are described in the Online resource 2. That allows notably labeling a large active treatment phase taking into account postpone treatment due to chemotherapy complications without considering surveillance alone. Index date was chosen 21 days before the first ICD-10 lymphoma code to take into account all potential clinical examinations related to diagnosis of lymphoma before the first lymphoma related hospitalization. The posttreatment period long were chosen to take into account the 
different healthcare courses of lymphoma sub-types, notably the maintenance therapy for $\mathrm{FL}$, and the variability of manQ3 agement according to patients.

We did not consider T-cell lymphoma because algorithm cannot identify them correctly given their particular healthcare management. Besides, we have not considered others B-Cell lymphoma to avoid misclassification bias and because FL and DLBCL are globally representatives of B-NHL management (i.e. indolent and aggressive lymphomas). For each case, we have randomly selected from the EGB 4 controls among patients not suffering from lymphoma to estimate the net cost of lymphoma. Controls were matched on gender and age. We did not use a propensity score to match our control according the low number to socio-demographic data we had. Control patients had the same index date of their associated cases and we have identified their healthcare consumptions during identical follow-up.

\subsection{Costs estimates}

Cost analysis was performed from the French health insurance perspective and included direct and sick leave compensation costs. Direct medical costs corresponded to the cost of health care consumption, represented by inpatient care and outpatient care. Inpatient stays cost take into account costs of hospitalization and costs of medicine delivered in inpatient setting. Outpatient care cost corresponds to the cost of visits, medical and paramedical procedures, outpatient drugs and medical equipment. Direct non-medical costs were limited to transportation costs and are detailed in the database according to the type of transport used. Sick leave compensation costs are represented by the patient's earning lost because of the illness. These costs are represented by daily allowance and disability pension. These costs are compensated to the patient by the French health insurance according to the amount of day absence of work. Daily allowance corresponds to the cost associated to short term sick leave and disability pension correspond to the cost associated to long term sick leave. All these data are available in the EGB databases with detailed fees (classification codes, quantities, unit costs, reimbursement costs...). Costs were estimated by multiplying the number of resources used by the corresponding reimbursement tariff given by the French health insurance (Online resource 3 ).

In France, public and private hospital fees are based on DRG tariffs which can be added by various supplements as expensive drugs like rituximab or medicine with special constraints of distribution, dispensation or administration which are hospital-reserved drugs. Expensive drugs are delivered only during inpatients stay. Hospital-reserved drugs are dispensed in outpatient setting by hospital pharmacy. Nevertheless, we have classified this medication within inpatient category. According to the huge weight of expensive medication in B-NHL management (i.e. rituximab), inpatient care was disaggregated into hospitalization costs and additional medicines (expensive and hospital-reserved drugs), which are funded in addition to hospitalization cost. DRG tariffs include also price of medication administered (i.e. chemotherapies) when it is not included as additional medicines.

Outpatient cares were valued according to the French Common Classification of Medical Acts (CCAM). Medication and medical equipment were valued with the French health insurance tariffs. Transportations, paramedical acts and visits were valued using the General Classification of Professional Act (NGAP). Costs linked to productivity loss were valued using the daily benefits given by the health insurance for short absences in the workplace and using disability pension for long-term sick leave.

Additional medicines were divided into rituximab and other medicines to allow rituximab weight assessment in the B-NHL management cost. DRG were split into 4 classes: lymphoma's diagnoses, lymphoma's treatments, lymphoma's complications and other hospitalizations. All inpatient stays combining both lymphoma's treatments and lymphoma's complications or diagnoses are grouped in lymphoma's treatments category. Outpatient medications were categorized using the main ATC (Anatomical Therapeutic Chemical) classification groups ${ }^{24}$.

All costs were inflated to corresponding 2018 prices using the French Consumer Price Index (CPI) from the Organization for Economic Co-operation and Development (OECD) website $^{25}$.

\subsection{Others data}

We have derived baseline comorbidities and Charlson Comorbidity Index $(\mathrm{CCl})$ from Bannay et al. paper during the year before index date for both cases and controls ${ }^{26}$. They use medical procedures, drugs and discharge diagnosis in hospital in addition to LTD scheme to identify the comorbidities and the $\mathrm{CCl}$. Finally, they apply new weights to a better assessment of $\mathrm{CCl}$. The related comorbidities identification algorithm and the new weights are descripted in Bannay et al. and were implemented in the EGB for cases and controls. Length of the active treatment phase and place of management (i.e. private vs public) were also described for lymphoma patients. Place of management was defined according to where the patient is treated. This information is known in the EGB database.

Patients who died during the active treatment phase have been maintained in the analysis and we did not stop active treatment phase before date of death. Indeed, we aimed to assess real-world cost due to lymphoma. If death occurs during the active treatment phase, it occurs during the last inpatient stay with a discriminant code of lymphoma. If the death occurs after the end of the active treatment phase, costs of end of life were not taken into account in the cost calculation. Nevertheless, the death variable will be used as adjustment variable to take into account the high costs due to end of life.

\subsection{Statistical analysis}

Descriptive statistics were used to summarize the data and included mean \pm Standard Deviation (SD) or quantiles, for 
continuous variables and occurrences with percentages for qualitative variables. Baseline characteristics were compared between lymphoma patients and controls using the Z-test for quantitative variables and Fisher's exact test for qualitative variables.

Lymphoma patient's costs were compared to those of the controls to estimate the additional cost of different lymphoma subgroups. Costs were monthly standardized to take into account the variability within the active treatment phases through lymphoma subtypes. Costs were described in terms of mean per patient and their Bias-Corrected and accelerated (BCa) bootstrap 95\% Confidence Intervals (CI) which adjusts for skewness distribution of cost. Depending on cost distribution, cost differences between lymphoma patients and their controls were tested using a statistical Z-Test or a Mann Whitney Wilcoxon non-parametric test.

A Generalized Linear Model (GLM) with gamma distribution and log link was implemented to adjust the cost differences between lymphoma subgroups with covariates. Age in quantile, gender, $\mathrm{CCl}$, state of life at the end of active treatment phase identified and the place of care were used as adjustments covariables. Age and gender were maintained in the model despite if they were non-significant. Statistical analyses were performed using $\mathrm{R}$ software (version 3.1.2).

\section{Results}

\subsection{Patient characteristics}

Lymphoma patients and controls identification are summarized in Figure 1 and descriptive statistics according to lymphoma sub-types are synthesized in Table 1. All comorbidities are summarized in the Supplementary files (Online resource 4).

The mean age of HL, FL and DLBCL patients was respectively $46.9 \pm 19,63 \pm 13.2$ and $65.9 \pm 16.1$ years with $40.4 \%$, $46.9 \%$ and $55.3 \%$ of women. HL and DLBCL patients had not significantly higher $\mathrm{CCl}$ than controls $(p=.172, p=.084)$ contrary to FL patients $(p<.01)$. This significant difference principally came from the important number of others cancer types in FL group (Online resource 3). Furthermore, DLBCL controls have higher proportion of diabetes than cases. The mean follow-up with the first and third quantile were respectively 199 days [155; 253], 419 days $[104 ; 860]$ and 186 [126; 232] for $\mathrm{HL}, \mathrm{FL}$ and $\mathrm{DLBCL}$ patients. Management by private hospital structures accounted between $9 \%$ for $\mathrm{FL}$ and $13.5 \%$ for DLBCL. We observed that $16.5 \%$ of DLBCL patients are dead between the last inpatient stay related to code of lymphoma and the 3 following months.

\subsection{Cost analysis}

Mean additional costs due to $\mathrm{HL}, \mathrm{FL}$ and $\mathrm{DLBCL}$ patients were respectively $€ 32,832$, 444,539 and $€ 46,708$ for the active treatment phase. When monthly standardized, mean additional costs due to $\mathrm{HL}, \mathrm{FL}$ and $\mathrm{DLBCL}$ patients were respectively equal to $€ 4,478, € 3,820$ and $€ 7,526$ (Table 2). The main cost drivers were inpatient stay, medication, and productivity loss. All significant cost differences between lymphomas and controls are detailed in the online Supplementary material (Online resource 5).

Inpatient stay was the most important cost driver amounted to a significant mean additional cost per month per patient $(p<.001)$ of respectively $€ 2,980, € 3,115$ and $€ 5,931$ for $\mathrm{HL}, \mathrm{FL}$ and DLBCL patients. These additional costs were mainly led by: (1) hospitalization costs (DRG tariffs) arising from the treatment, especially for DLBCL with $€ 2,167$ and for $\mathrm{HL}$ patients with $€ 1,124$; (2) additional medicine coming from rituximab for $\mathrm{FL}$ and $\mathrm{DLBCL}$ patients with respectively $€ 1,511$ and $€ 2,284$.

The second most important cost driver was outpatient medication which amounted to a significant mean additional cost per month per patient $(p<.001)$ of respectively $€ 560$, $€ 365$ and $€ 858$ for $\mathrm{HL}, \mathrm{FL}$ and $\mathrm{DLBCL}$ patients. These additional costs were firstly led by antineoplastic and immunomodulators drug costs which were mainly composed by the three following growth factor drugs (ATC code: L03AA): filgrastim, lenograstim and pegfilgrastim. Secondly, drug costs were explained by blood and hematopoietic organs drugs which are driven by the antianemic preparations (ATC code: B03).

The third main cost driver comes from productivity loss which amounted to a significant mean additional cost per month per patient $(p<.001)$ equal to $€ 464$, $€ 136$ and $€ 229$ for respectively $\mathrm{HL}, \mathrm{FL}$ and $\mathrm{DLBCL}$ and led by the daily allowance.

Table 3 shows the cost variations associated to lymphoma subtypes. The $\mathrm{CCl}$ was not significant in both univariate and multivariate analysis and was excluded from the model. DLBCL patients are associated with a significant higher monthly cost of healthcare management than FL patients $(\mathrm{RR}=1.87 ; 95 \% \mathrm{Cl}: 1.53 ; 2.28, p<.001)$. Patients who are managed in private hospital are associated with a $26 \%$ cost decrease than patients who are managed in public hospital $(\mathrm{RR}=0.74 ; 95 \% \mathrm{Cl}: 0.57 ; 0.95, p=.020)$ and patients who died at the end of the active treatment phase incur a cost increase of $78 \%(\mathrm{RR}=1.78,95 \% \mathrm{Cl}: 1.37 ; 2.32, p<.001)$.

\section{Discussion}

This is the first study which assesses the lymphoma related cost in France, using French health insurance databases. Mean additional costs due to $\mathrm{HL}, \mathrm{FL}$ and DLBCL patients were respectively $€ 32,832$, $€ 44,539$ and $€ 46,708$ for the active treatment phase. When monthly standardized, mean additional costs due to $\mathrm{HL}, \mathrm{FL}$ and $\mathrm{DLBCL}$ patients were respectively equal to $€ 4,478, € 3,820$ and $€ 7,526$. The main cost drivers were inpatient stays, medication, and productivity loss. When adjusted we observed that DLBCL incurs the most important cost per month.

Only few data are available on the COI of lymphoma subtypes using population based data. Five studies were found in North America and one in Europe. American studies were focused on $\mathrm{HL}, \mathrm{DLBCL}$ or $\mathrm{FL}$ patients according to special treatments or line of treatments ${ }^{14-18}$. Moreover, the healthcare system in the US or Canada is considerably different 


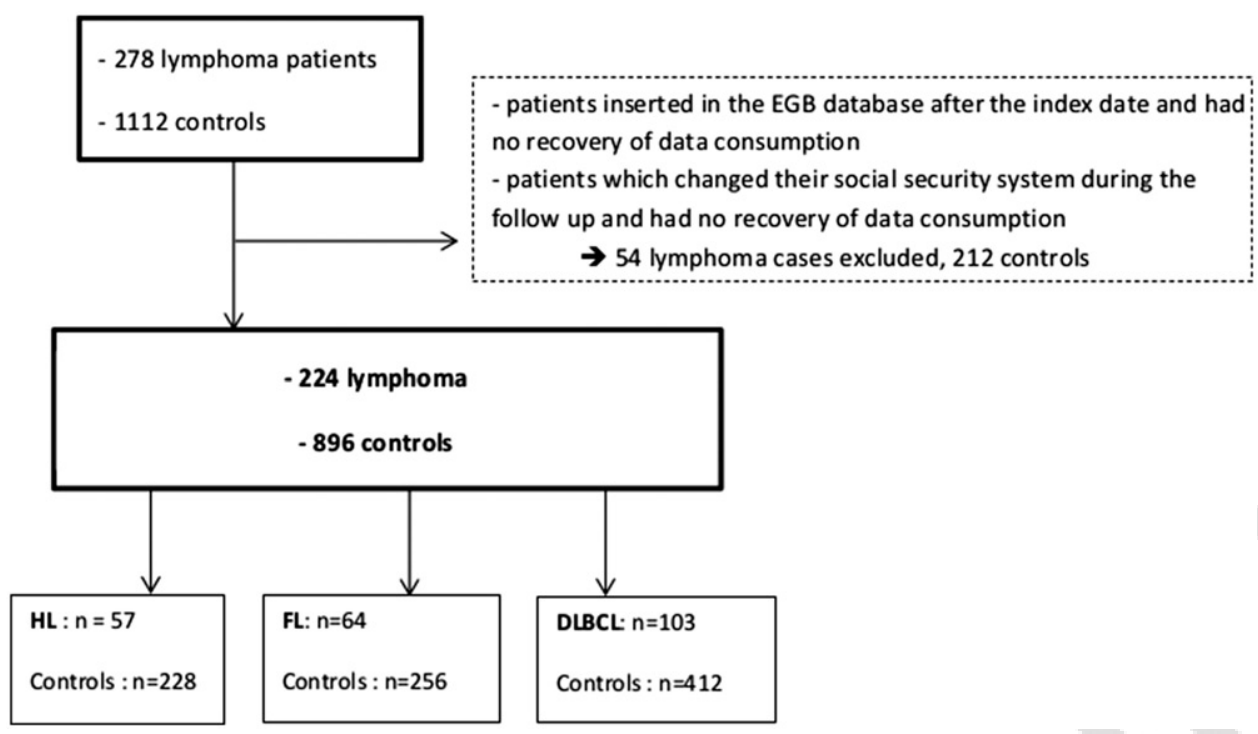

Figure 1. Identification of lymphoma and controls population. Abbreviations. HL, Hodgkin Lymphoma; FL, Follicular Lymphoma; DLBCL, Diffuse Large B-Cell Lymphoma.

Table 1. Baseline characteristics according to lymphoma subgroups ( $\mathrm{HL}$ and B-NHL).

\begin{tabular}{|c|c|c|c|c|c|c|c|c|c|}
\hline & \multicolumn{3}{|c|}{$\mathrm{HL}$} & \multicolumn{3}{|c|}{$\mathrm{FL}$} & \multicolumn{3}{|c|}{ DLBCL } \\
\hline & Cases $(n=57)$ & Controls $(n=228)$ & $p$ & Cases $(n=64)$ & Controls $(n=256)$ & $p$ & Cases $(n=103)$ & Controls $(n=412)$ & $p$ \\
\hline Age (mean, (sd)) & $46.9(19.0)$ & $46.9(19.0)$ & 1 & $63(13.2)$ & $63(13.2)$ & 1 & $65.9(16.1)$ & $65.9(16.1)$ & 1 \\
\hline Gender (women, (\%)) & $23(40.4)$ & $92(40.4)$ & 1 & $30(46.9)$ & $120(49.6)$ & 1 & $57(55.3)$ & $228(55.3)$ & 1 \\
\hline \multicolumn{10}{|l|}{$\mathrm{CCl}(n,(\%))$} \\
\hline 0 & $47(82.5)$ & $201(88.2)$ & .172 & $41(64.1)$ & $204(79.7)$ & .009 & $75(72.8)$ & $337(81.8)$ & .084 \\
\hline $1-2$ & $7(12.3)$ & $23(10.1)$ & & $18(28.1)$ & $43(16.8)$ & & $20(19.4)$ & $57(13.8)$ & \\
\hline $3-4$ & $1(1.8)$ & $3(1.3)$ & & $3(4.7)$ & $9(3.5)$ & & $5(4.9)$ & $15(3.6)$ & \\
\hline 5 & $2(3.5)$ & $1(0.4)$ & & $2(3.1)$ & $0(0)$ & & $3(2.9)$ & $3(0.7)$ & \\
\hline Management by Private & $6(10.5)$ & & & $6(9)$ & & & $14(13.5)$ & & \\
\hline Death* $^{*}(\mathrm{n}(\%))$ & $3(5.3)$ & & & $4(6.3)$ & & & $17(16.5)$ & & \\
\hline Follow-up (mean, [Q1-Q3]) & \multicolumn{3}{|c|}{199 [155; 253] } & \multicolumn{3}{|c|}{$419[104 ; 860]$} & \multicolumn{3}{|c|}{$186[126 ; 232]$} \\
\hline
\end{tabular}

Abbreviations. HL, Hodgkin Lymphoma; FL, Follicular Lymphoma; DLBCL, Diffuse Large B Cells Lymphoma; CCl, Charlson Comorbidity Index; $p, p$-value; ${ }^{*}$ Death 3 months after the end of active treatment phase.

than the French healthcare system especially because of health care organization, reimbursement conditions and different unit prices used to value healthcare resources which makes harder the comparison between studies. According to the European context, Wang et al. used decision model to predict cost of DLBCL patient based on the UK's population based database ${ }^{13}$. They were focused on costs of diagnosis, treatment, supportive care, follow-up and end-of-life care. They have estimated life time costs of patient treated with first line treatment to $£ 22,122$. Our results are higher despite the lower follow up we used. That may be explained by the larger part of cost component we took into account. Unfortunately, authors did not detail all inpatient cost components and we cannot compare our results.

There is a lack of economic evaluation of lymphoma in France. We reviewed only two studies on the topic ${ }^{19,20}$. These studies are cost effectiveness studies which mainly focus on rituximab cost. Best et al. in 2005 assessed the cost of DLBCL patients from the French payer perspective and treated by rituximab to $€ 41,952$ over 15 years with $33.6 \%$ due to rituximab. Our results are quite similar considering that we took into account larger magnitude of cost component while they considered a larger follow-up period.
Deconinck et al. in 2010 estimated the cost of FL treated with Rituximab during maintenance therapy. Nowadays maintenance therapy with rituximab is considered as a standard of care and we consider it as a part of active treatment phase ${ }^{27}$. Furthermore, both of these studies have considered French healthcare perspective but they did not only use French data.

Our study is the first which assesses $\mathrm{HL}, \mathrm{FL}$ and $\mathrm{DLBCL}$ related cost in France, using real-world population-based data. In a context where decision makers are increasing interest for RWE, our study provides detailed economic information about HL and the main NHL subtype's management. Our finding spotlight where management could be improved in terms of quality of care and cost saving.

According to our model, we have identified a $26 \%$ cost decrease if the patient is managed in private hospital. Firstly, private hospitals attract generally patients with higher socioeconomic level, better survival prognosis and less complicated management. In private hospital setting, patients spend less, meet fewer and less critical AEs. Furthermore, private and public hospitals are not subject to the same funding rules $^{28}$. Finally, we have to be caution because of the lack of statistical power depending to the small proportion 


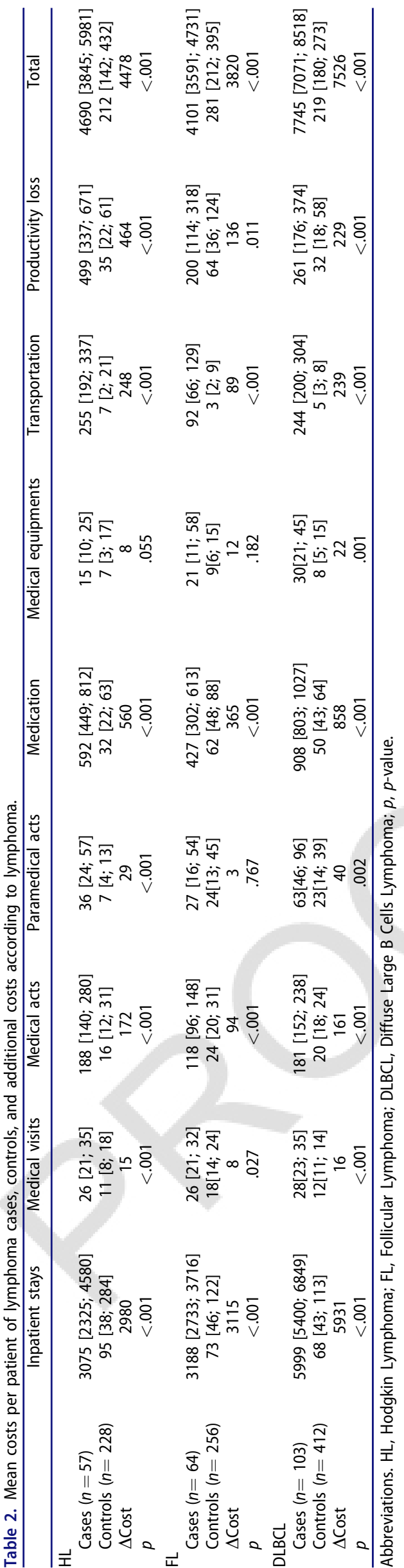

Table 3. Gamma multivariate regression model on additional cost of lymphoma.

\begin{tabular}{|c|c|c|c|}
\hline$\overline{\text { Variable }}$ & RR & $\mathrm{Cl}(95 \%)$ & $p$ \\
\hline \multicolumn{4}{|l|}{ Age } \\
\hline$[18 ; 55]$ & 1 & & \\
\hline$[56 ; 70]$ & 1.00 & {$[0.81 ; 1.24]$} & .983 \\
\hline$[71 ; 89]$ & 0.85 & {$[0.68 ; 1.05]$} & .136 \\
\hline \multicolumn{4}{|l|}{ Gender } \\
\hline Female & 1.01 & {$[0.86 ; 1.19]$} & .869 \\
\hline \multicolumn{4}{|l|}{ Life State } \\
\hline Death & 1.78 & {$[1.37 ; 2.32]$} & $<.001^{* *}$ \\
\hline \multicolumn{4}{|c|}{ Place of management } \\
\hline Private & 0.74 & {$[0.57 ; 0.95]$} & $.020^{*}$ \\
\hline \multicolumn{4}{|c|}{ Lymphoma subtype } \\
\hline $\mathrm{FL}$ & 1 & & \\
\hline $\mathrm{HL}$ & 1.11 & {$[0.88-1.4]$} & .383 \\
\hline DLBCL & 1.87 & {$[1.53-2.28]$} & $<.001^{* *}$ \\
\hline
\end{tabular}

Abbreviations. HL, Hodgkin Lymphoma; $\mathrm{FL}$, Follicular Lymphoma; $\mathrm{DLBCL}$, Diffuse Large B-Cell Lymphoma; RR, Relative Risk; $p$, $p$-value. ${ }^{*} p<.05 ;{ }^{*} p<.001$.

of patients treated in private hospital. Thus, this variable has to be considered rather an adjustment covariable than a covariable of interest.

We noticed that DLBCL are significantly the most costly lymphoma. Related expenditures are mainly lead by rituximab. This cost could be largely reduced in the future, especially with the recent availability of two biosimilars in France, truxima ${ }^{\circledR}$ and rixathon ${ }^{\circledR}$ in 2017. According to the European Society for Medical Oncology (ESMO), biosimilar medications present a necessary and timely opportunity for physicians, patients and healthcare systems ${ }^{29}$. This medication could lead to an important cost saving but naturally depending on the extent of biosimilar adoption ${ }^{30}$. Physicians and patients express reservations regarding biosimilar efficacy, safety and cost saving ${ }^{31}$. In this context, RWE provided in our study will be helpful to assess the budget impact or cost-effectiveness associated with these biosimilars. Findings associated may help to convince stakeholders about biosimilar benefit in real-world setting and to enhance product uptake ${ }^{32}$. As a comparison, an Italian study has investigated the 5-year budget impact of rituximab biosimilars ${ }^{33}$. Using the hospital perspective, they have estimated produce savings of respectively $€ 79.2$ and $€ 153.6$ million over 3 and 5 years. Furthermore, in France biosimilar of growth factor as filgrastim are available since 2013. Nevertheless, according to the French National Agency for Medicines and Health Products Safety, only $28 \%$ of administrated growth factors were biosimilar in $2015^{34}$. It could be an important way to optimize lymphoma management, medication lead by these drugs being the second cost driver in our study.

We have observed a high inpatient's DRG cost related to hospitalization stay for treatment, notably for DLBCL patients $(€ 2,167)$. This cost is mainly determined by the duration of hospital stay that is longer than one night $(€ 1,742)$, while chemotherapy is generally administered in day hospitalization setting. Chemotherapy is toxic and the resulting complications occur frequently during a cycle of chemotherapy. Nevertheless, they are managed at the following admission for chemotherapy administration, which explains these results and justifying the low cost related to complications alone. That highlights the need to prevent avoidable 
complications to reduce this cost with promoting telemedicine programs or improving therapeutic patient education $^{35-37}$. In this context, a better management of AEs could leads to improve of patient quality of life, reduce day absence from work and decrease productivity loss related cost, the third cost driver in our study ${ }^{38}$. In addition, subcutaneous rituximab instead intravenous rituximab could reduce treatment burden for $\mathrm{B}-\mathrm{NHL}$ patient and improve resource utilization $^{39}$.

The main strength of our study is the use of real-life data with a population-based reimbursement database. The French health insurance databases are the best population based data source for performing economic studies in France $^{22}$. It provides exhaustive reimbursement data of the healthcare consumption of a large part of French population with detailed inpatient and outpatient financial data which allows thorough analysis. The second main strength of our work is the use of a validated algorithm to select our population. The validation study shows a great sensibility of the algorithm allowing a correct identification of cases. In addition, false negative may concern patients never hospitalized for their lymphoma because different disease management or a gap between diagnosis and treatment ${ }^{23}$. Thus, according to the exhaustiveness of health care consumption in the $E G B$, the use of validated algorithm to these data are a great of interest to conduct economic evaluation.

Our results present some limitations. The first one is due to the high misclassifications rate on lymphoma sub-types: approximately $20 \%$ of diagnoses change after an expert review and the most frequent discrepancies were among lymphoma sub-types (i.e. $41.3 \%)^{40}$. We have defined which subgroups of lymphoma patient belongs according to type, number and recency of ICD-10 code found to avoid it. In addition, we have arbitrary chosen 12 week's long for the post-treatment period to conclude about the end of active treatment phase. That allows taking into account the large gaps between guidelines and the practice arising from patient and hospital characteristics and affecting treatment adherence $^{41}$. Nevertheless, we cannot point out and exclude relapsed patients who have switched to second/salvage therapy during the post-treatment period. That could lead to consider few patients which early relapsed and started a second active treatment phase and an overestimation of our results. However, overestimation is small according to the limited number of relapsed lymphoma patients during the post-treatment period and according to the monthly standardized cost we used in analysis ${ }^{42-44}$. Identification algorithm is based on inpatient stay for diagnosis or treatment. Thus, we could have missed untreated patient or patient with gap between diagnosis and treatment as FL in observation phase $^{23}$. It is the main reason why we did not take into account T-NHL and chronic lymphocytic leukemia which are sometimes not managed in inpatient setting. Nevertheless $\mathrm{HL}, \mathrm{DLBCL}$ and treated FL are mainly managed in inpatient setting and algorithm used present good performances according detection of these pathologies.

In a context where decision maker increasing interest for RWE, our study provide important information with high magnitude of details on lymphoma related costs that will help health policy to better understand the healthcare management of lymphoma ${ }^{12}$. Our results highlight the huge weight of rituximab in the total cost of B-NHL. This cost component can be largely reduced with upcoming biosimilars. We have notably planned to assess economic impact of these drugs with our results to develop a cost-minimization analysis using an agent-based simulation model. In addition, we highlight the crucial need to improve adverse event management by preventing avoidable complications. This study shows the strength to work with a powerful tool as the health insurance database using validated algorithm to supply useful RWE information for assessing novelties in healthcare management.

\section{Transparency}

\section{Declaration of funding}

This work received support from the National Research Agency (Agence Nationale de la Recherche (ANR)) for the "investissement d'avenir" ("Investment in the Future") (ANR-11-PHUC-001).

\section{Declaration of financial/other relationships}

The authors declare that they have no conflict of interest. JME peer reviewers on this manuscript have no relevant financial or other relationships to disclose.

\section{Author contributions}

All authors have participated in the work and have reviewed and approved the content of the article.

\section{Acknowledgements}

No assistance in the preparation of this article is to be declared.

\section{ORCID}

Michael Mounié (ID) http://orcid.org/0000-0003-0298-267X

\section{References}

[1] Roman E, Smith AG. Epidemiology of lymphomas. Histopathology. 2011;58(1):4-14.

[2] Ferlay J, Steliarova-Foucher E, Lortet-Tieulent J, et al. Cancer incidence and mortality patterns in Europe: estimates for 40 countries in 2012. Eur J Cancer. 2013;49(6):1374-1403.

[3] Chihara D, Nastoupil L, Williams JN, et al. New insights into the epidemiology of non-Hodgkin lymphoma and implications for therapy. Expert Rev Anticancer Ther. 2015;15(5):531-544.

[4] Monnereau A, Uhry Z, Bossard N, et al. Survie des personnes atteintes de cancer en France métropolitaine, 1989-2013. Partie 2 - Hémopathies malignes. Saint-Maurice: Institut de veille sanitaire; 2016.

[5] Institut Universitaire du Cancer de Toulouse. Référentiel régional. Traitement des LYMPHOMES de I'ADULTES. [cited 2018 Jan]. Available from: https://www.onco-occitanie.fr/system/files/201904/R\%C3\%A9f\%C3\%A9rentiel_Lymphome_Juillet2018.pdf.

[6] Ansell SM. Hodgkin lymphoma: diagnosis and treatment. Mayo Clin Proc. 2015;90(11):1574-1583. 
[7] Ansell SM. Non-hodgkin lymphoma: diagnosis and treatment. Mayo Clin Proc. 2015;90(8):1152-1163.

[8] Kasi PM, Tawbi HA, Oddis CV, et al. Clinical review: serious adverse events associated with the use of rituximab - a critical care perspective. Crit Care. 2012;16(4):231.

[9] Mojs E, Warchoł-Biedermann K, Samborski W. What do we know about psychological outcomes of lymphoma in adults? Eur Psychol. 2017;22(2):121-131.

[10] Byford S, Torgerson DJ, Raftery J. Economic note: cost of illness studies. BMJ. 2000;320(7245):1335.

[11] Koopmanschap MA. Cost-of-illness studies. Useful for health policy? Pharm Eco. 1998;14(2):143-148.

[12] Romio S, Sturkenboom M, Corrao G. Real-world data from the health decision maker perspective. What are we talking about? Epidemiol Biostatistics Pub Health. 2013;10:3.

[13] Wang HI, Roman E, Crouch S, et al. A generic model for follicular lymphoma: predicting cost, life expectancy, and quality-adjustedlife-year using UK population-based observational data. Value Health. 2018;21(10):1176-1185.

[14] Morrison VA, Bell JA, Hamilton L, et al. Economic burden of patients with diffuse large B-cell and follicular lymphoma treated in the USA. Future Oncol. 2018;14(25):2627-2642.

[15] Shao C, Liu J, Zhou W, et al. Treatment patterns, health care resource utilization, and costs in patients with relapsed/refractory Hodgkin lymphoma treated with brentuximab vedotin. Leuk Lymphoma. 2018;60(4):947-954.

[16] Bonafede M, Feliciano J, Cai Q, et al. Real-world analysis of cost, health care resource utilization, and supportive care in Hodgkin lymphoma patients with frontline failure. CEOR. 2018;10:629-641.

[17] Maziarz RT, Hao Y, Guerin A, et al. Economic burden following allogeneic hematopoietic stem cell transplant in patients with diffuse large B-cell lymphoma. Leuk Lymphoma. 2018;59(5): 1133-1142.

[18] Khor S, Beca J, Krahn M, et al. Real world costs and cost-effectiveness of Rituximab for diffuse large B-cell lymphoma patients: a population-based analysis. BMC Cancer. 2014;14(1):586.

[19] Best JH, Hornberger J, Proctor SJ, et al. Cost-effectiveness analysis of rituximab combined with chop for treatment of diffuse large B-cell lymphoma. Value Health. 2005;8(4):462-470.

[20] Deconinck E, Miadi-Fargier H, Pen CL, et al. Cost effectiveness of rituximab maintenance therapy in follicular lymphoma: long-term economic evaluation. Pharmacoeconomics. 2010;28(1):35-46.

[21] Bezin J, Duong $M$, Lassalle $R$, et al. The national healthcare system claims databases in France, SNIIRAM and EGB: Powerful tools for pharmacoepidemiology. Pharmacoepidemiol Drug Saf. 2017; 26(8):954-962.

[22] Moulis G, Lapeyre-Mestre M, Palmaro A, et al. French health insurance databases: what interest for medical research? Rev Med Interne. 2015;36(6):411-417.

[23] Conte C, Palmaro A, Grosclaude P, et al. A novel approach for medical research on lymphomas: a study validation of claimsbased algorithms to identify incident cases. Medicine. 2018;97(2): e9418.

[24] Anatomical Therapeutic Chemical Classification. [cited 2017 Jun 1]. Available at: http://ec.europa.eu/health/documents/community-register/html/atc.htm.

[25] Organisation for Economic Co-operation and Development (OECD). Anon. 4. PPPs and exchange rates. [cited 2017 Jun 1]. Available at: https://stats.oecd.org/Index.aspx?DataSetCode=SNA_ TABLE4.
[26] Bannay A, Chaignot C, Blotière PO, et al. The best use of the charlson comorbidity index with electronic health care database to predict mortality. Med Care. 2016;54(2):188-194.

[27] Salles G, Seymour JF, Offner F, et al. Rituximab maintenance for 2 years in patients with high tumour burden follicular lymphoma responding to rituximab plus chemotherapy (PRIMA): a phase 3 , randomized controlled trial. Lancet. 2011;377(9759):42-51.

[28] Brigitte D, Carine M. ÉCONOMIE ET STATISTIQUE N 455-456, 2012. Comment évaluer la productivité et l'efficacité des hôpitaux publics et privés? Les enjeux de la convergence tarifaire.

[29] Tabernero J, Vyas M, Giuliani R, et al. Biosimilars: a position paper of the European Society for Medical Oncology, with particular reference to oncology prescribers. ESMO Open. 2017;1(6):e000142.

[30] Ronnebaum S, Atzinger C. Enhancing Biosimilar Adoption With Real-World Evidence. Health Economics and Outcomes Research (HEOR) article. July/August 2018. Value \& Outcomes Spotlight.

[31] Dolan C. Opportunities and challenges in biosimilar uptake in oncology. Am J Manag Care. 2018;24(11):S237-S243.

[32] Simoens S, Jacobs I, Popovian R, et al. Assessing the value of biosimilars: a review of the role of budget impact analysis. Pharmaco Eco. 2017;35(10):1047-1062.

[33] Rognoni C, Bertolani A, Jommi C. Budget impact analysis of rituximab biosimilar in Italy from the hospital and payer perspectives. Global Regional Health Technol Assessment. 2018.

[34] French National Agency for Medicines and Health Products Safety. 2016. État des lieux sur les medicaments biosimilaires. Available from: https://www.ansm.sante.fr/content/download/ 88209/1110173/version/1/file/Rapport-biosimilaires-2mai2016.pdf.

[35] Compaci G, Ysebaert L, Obéric L, et al. Effectiveness of telephone support during chemotherapy in patients with diffuse large $B$ cell lymphoma: the Ambulatory Medical Assistance (AMA) experience. Int J Nurs Stud. 2011;48(8):926-932.

[36] Sirintrapun SJ, Lopez AM. Telemedicine in cancer care. Am Soc Clin Oncol Educ Book. 2018;38:540-545.

[37] World Health Organization. Therapeutic Patient Education Continuing Education Programmes for Health Care Providers in the Field of Prevention of Chronic Diseases. 1998.

[38] Kamal KM, Covvey JR, Dashputre A, et al. A systematic review of the effect of cancer treatment on work productivity of patients and caregivers. JMCP. 2017; 23(2):136-162.

[39] Davies A, Berge C, Boehnke A, et al. Subcutaneous rituximab for the treatment of B-Cell hematologic malignancies: a review of the scientific rationale and clinical development. Adv Ther. 2017 34(10):2210-2231.

[40] Laurent C, Baron M, Amara N, et al. Impact of expert pathologic review of lymphoma diagnosis: study of patients from the French lymphopath network. JCO. 2017;35(18):2008-2017.

[41] Stienen JJ, Hermens RP, Wennekes L, PEARL study group, et al. Variation in guideline adherence in non-Hodgkin's lymphoma care: impact of patient and hospital characteristics. BMC Cancer. 2015;15(1):578.

[42] Feldman T, Gromko L, Protomastro EA, et al. Relapses of diffuse large $B$ cell lymphoma in rituximab era are limited to the first two years after frontline therapy. Blood. 2014;124(21):1307.

[43] Casulo C, Byrtek M, Dawson KL, et al. Early relapse of follicular lymphoma after rituximab plus cyclophosphamide, doxorubicin, vincristine, and prednisone defines patients at high risk for death: an analysis from the National LymphoCare Study. JCO. 2015; 33(23):2516-2522.

[44] Montanari F, Diefenbach C. Relapsed Hodgkin lymphoma: management strategies. Curr Hematol Malig Rep. 2014;9(3):284. 